\title{
Risk of Direct Oral Anticoagulant Bioaccumulation in Patients with Pulmonary Hypertension
}

\author{
Laurence Gabriel $^{\mathrm{a}}$ Xavier Delavenne ${ }^{\mathrm{a}, \mathrm{b}}$ Pierrick Bedouch ${ }^{c}$ Chahéra Khouatra $^{\mathrm{d}}$ \\ Hélène Bouvaist ${ }^{e}$ Jean-François Cordier ${ }^{f}$ Jean-François Mornex ${ }^{f}$ \\ Christophe Pison ${ }^{g-j}$ Vincent Cottin ${ }^{f}$ Laurent Bertoletti ${ }^{b, k, l}$
}

a Laboratoire de Pharmacologie, Toxicologie et Gaz du Sang, CHU Saint-Etienne, and ${ }^{\text {b } D y s f o n c t i o n ~ V a s c u l a i r e ~}$ et Hémostase, U1059, INSERM, Université Jean-Monnet, Saint-Etienne, 'Pharmacie, CHU Grenoble, Pharmacy Department, Université Grenoble Alpes/CNRS/TIMC-IMAG, UMR 5525/Themas, Grenoble, 'Centre de Compétences de I'Hypertension Artérielle Pulmonaire, Centre de Référence National des Maladies Pulmonaires Rares, Lyon, ${ }^{e} \mathrm{Clinique}$ Universitaire de Cardiologie, Pôle Thorax et Vaisseaux, CHU Grenoble, Grenoble, ${ }^{\mathrm{f} U n i v e r s i t e ́ ~ d e ~ L y o n, ~ U n i v e r s i t e ́ ~ L y o n ~}$ 1, INRA, UMR754 INRA, Centre de Compétences de I'Hypertension Artérielle Pulmonaire, Centre de Référence National des Maladies Pulmonaires Rares, Lyon, ${ }^{9}$ Clinique Universitaire de Pneumologie, Pôle Thorax et Vaisseaux, CHU Grenoble, 'h Université Grenoble Alpes, and 'U1055, INSERM, Grenoble, 'jEuropean Institute of Systems Biology and Medicine, Lyon, ' Service de Médecine Vasculaire et Thérapeutique, CHU Saint-Etienne, and 'CIC1408, INSERM, Saint-Etienne, France

\section{Key Words}

Pulmonary arterial hypertension · Pulmonary hypertension · Anticoagulant · Venous thromboembolism · Atrial

fibrillation · Vitamin K antagonists · Direct oral anticoagulant

\begin{abstract}
Background: Patients treated for pulmonary arterial hypertension (PAH) frequently receive vitamin $\mathrm{K}$ antagonists (VKAs) for PAH or validated indications (such as atrial fibrillation or venous thromboembolism). In these latter indications, VKAs are challenged by direct oral anticoagulants (DOAs). Decreased dosage of DOAs has been proposed in patients at risk of bioaccumulation. Objectives: We aimed to evaluate the frequency of bioaccumulation risks in patients treated with $\mathrm{PAH}$-targeted therapy, particularly regarding the presence of validated indications. Methods: We con-
\end{abstract}

ducted a retrospective study in three different $\mathrm{PAH}$ referral centers. All patients receiving PAH-targeted therapy were classified according to demographics, prescription and indications of VKAs, and the presence of major bioaccumulation risk factors (renal failure, low body weight, strong P-glycoprotein or cytochrome P3A4 inhibitors). Results: Two hundred and thirty-nine of the 366 patients included received VKAs, 94 for validated indications. At least one major risk factor was found in 231 (63.1\%) of the whole study population, and in $54(57.4 \%)$ of the patients anticoagulated for a validated indication. No specific patient phenotype could be individualized. Conclusions: About 1 in 2 patients treated with $\mathrm{PAH}$ therapy has at least one of the three major risk factors for DOA bioaccumulation. DOAs in the $\mathrm{PH}$ setting could be associated with bioaccumulation and should be individualized, mainly in patients with confirmed indication.

(C) 2016 S. Karger AG, Base

\section{KARGER}

E-Mail karger@karger.com

www.karger.com/res
(C) 2016 S. Karger AG, Basel

0025-7931/16/0914-0307\$39.50/0
Laurent Bertoletti

Service de Médecine Vasculaire et Thérapeutique, CHU Saint-Etienne Avenue Albert Raimond

FR-42055 Saint-Etienne CEDEX 2 (France)

E-Mail laurent.bertoletti@gmail.com 


\section{Introduction}

Pulmonary arterial hypertension $(\mathrm{PAH})$ is a rare disease characterized by a progressive increase in pulmonary vascular resistance, leading to right ventricle failure and premature death [1]. Pathogenic pathways include vascular remodeling, vasoconstriction, and thrombotic lesions [2]. Vitamin K antagonists (VKAs) are largely prescribed in patients with $\mathrm{PAH}$, based on the pathology findings, demonstration of a procoagulant imbalance and impairment of the fibrinolysis system [3]. For example, more than $90 \%$ of patients in the French registry received VKAs [4]. A recent meta-analysis [5] suggested a $31 \%$ of survival benefit in PAH patients receiving anticoagulant therapy. However, these results merely rely on a recent post hoc analysis of patients included in the COMPERA registry [6]. Hence, the 2015 ESC/ERS guidelines provide a low-level of recommendation (IIb, C) for oral anticoagulant treatment in patients with idiopathic or heritable $\mathrm{PAH}$, or $\mathrm{PAH}$ associated with anorexigens [7].

Of note, patients with $\mathrm{PAH}$ [as those with other types of pulmonary hypertension $(\mathrm{PH})]$ may also receive VKAs for other indications: mostly atrial fibrillation (AF) or venous thromboembolism (VTE) including chronic thromboembolic $\mathrm{PH}(\mathrm{CTEPH})$ [8]. In these validated indications, anticoagulant therapy is associated with a reduction in mortality compared with placebo [9].

The management of treatment with VKAs remains difficult because of their narrow therapeutic window and high pharmacological variability (influenced by personal background [10], food or drug interactions). In patients with AF or VTE, direct oral anticoagulants (DOAs) including dabigatran $[11,12]$, rivaroxaban $[13$, 14], apixaban $[15,16]$, or edoxaban $[17,18]$ are recent alternatives to VKAs without laboratory monitoring, with at least similar efficacy, and a lower risk of major bleeding [19]. However, patients included in pivotal studies might have been selected to avoid the bioaccumulation risk of DOAs, therefore questioning the benefit/risk ratio in a wider population. DOAs have an important pharmacological variability. Their bioavailability is mainly influenced by body weight, drugs absorption, metabolism, and elimination. DOA absorption strongly depends on the membrane efflux transducer P-glycoprotein (Pgp), and their metabolic degradation mainly depends on cytochrome P3A4 (CYP3A4) activity in the liver. For example, one pill of clarithromycin, a strong Pgp inhibitor, increases the peak serum concen- tration of dabigatran and the area under the curve by 60.2 and $49.1 \%$, respectively, in healthy subjects [20]. All DOAs are eliminated by the kidneys. Their safety profile has therefore been linked to renal function [21].

Concerns have recently arisen regarding the risk of bleeding related to DOA bioaccumulation. In order to avoid such bioaccumulation, the design of edoxaban (the most recent DOA) phase III trials integrated a 50\% dose reduction in patients at risk of bioaccumulation. As an example, a patient included in the HOKUSAI trial received only $30 \mathrm{mg}$ of edoxaban in the presence of one of the following three bioaccumulation risk factors: body weight $<60 \mathrm{~kg}$, creatinine clearance $<50 \mathrm{ml} / \mathrm{min}$, concomitant treatment with a strong inhibitor [18]. The results of the ENGAGE and HOKUSAI trials validated this pharmacological strategy, particularly in terms of safety [22].

Data from studies in PAH patients are frequently extrapolated to other forms of $\mathrm{PH}$ [23]. Many patients with $\mathrm{PH}$ received off-label $\mathrm{PAH}$-targeted therapies. A retrospective study recently reported an unexpected high rate of major bleeding under VKAs in different settings of $\mathrm{PH}$ [24]. In order to decrease this bleeding risk, it seems predictable that patients with various forms of $\mathrm{PH}$ will receive DOAs for a validated indication, or off-label. Of note, PAH-targeted drugs also interact with DOAs: bosentan is a strong CYP3A4 inducer and a weak Pgp inducer [25], whereas sildenafil and tadalafil are weak inhibitors of CYP3A4. Moreover, the prevalence of moderate renal failure is unknown in patients with $\mathrm{PH}$.

Hence, the main objective of the present study was to determine the proportion of patients treated for $\mathrm{PH}$ who had at least one of the three major risk factors of DOA bioaccumulation, in a varied unselected set of patients treated for $\mathrm{PH}$, and particularly in those with a validated indication for anticoagulant therapy.

\section{Material and Methods}

\section{Population and Setting}

A retrospective cohort study was conducted in three sites of the Rhône-Alpes regional competence center: Lyon, Grenoble and Saint-Etienne University Hospitals. All ambulatory or hospitalized adult ( $>18$ years) patients with confirmed precapillary $\mathrm{PH}$ who received at least one PAH-specific medication between January and June 2013 were included. In the event of multiple visits, only data of the first visit were analyzed.

Since the objective of the study was to describe current practice, it is entirely observational. According to local legislation, this study has been declared to the Commission Nationale de l'Informatique et des Libertés. 
Table 1. Characteristics of the patient population

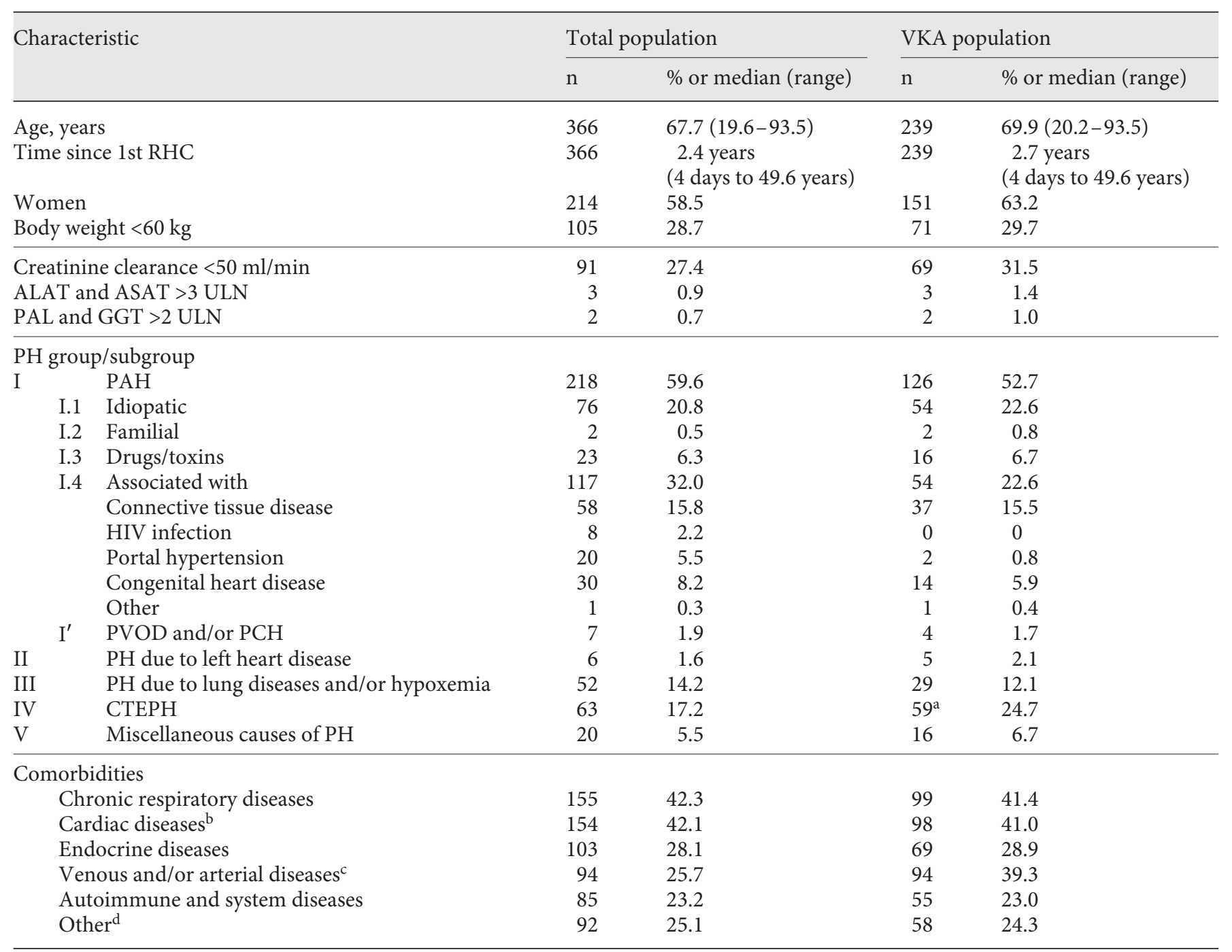

ALAT $=$ Alanine aminotransferase; ASAT $=$ aspartate aminotransferase; GGT $=\gamma$-glutamyl transferase; $\mathrm{PAL}=$ alkaline phosphatase; $\mathrm{PVOD}=$ pulmonary veno-occlusive disease $\mathrm{PCH}=$ pulmonary capillary hemangiomatosis; $\mathrm{RHC}=$ right heart catheterism; $\mathrm{ULN}=$ upper limit of normal. a Two other patients received DOAs for CTEPH, one only antiplatelet drug, and the last no antithrombotic drug. ${ }^{b}$ History of heart failure or myocardial infarction. ${ }^{c}$ Venous thromboembolism or arterial diseases with indication of oral anticoagulant. ${ }^{\mathrm{d}}$ Neuropsychological disorders, hematological diseases, chronic renal failure, liver diseases.

\section{Data Collection}

For each patient, data on $\mathrm{PH}$ and renal, hepatic, and hemostasis biology (up to 1 month prior to treatment initiation), drug treatment (PAH-targeted and supportive oral drugs), and indication of anticoagulants (a validated indication or for PAH) were collected in a case report form based on the hospital electronic patient chart, further completed by contacting the general practitioner, and transferred into an electronic database. Comorbidities were classified into six groups: chronic respiratory diseases, cardiac diseases, endocrine diseases, venous and/or arterial diseases, autoimmune and system diseases, and others (neuropsychological disorders, hematological diseases, chronic renal failure, liver diseases). PAH- targeted and supportive oral therapies (including anticoagulants with their indication) were collected at the time of consultation. In VKA patients, the INR evaluated at the time of inclusion was collected.

\section{Evaluation of Drug-Drug Interactions and Risk of DOA} Bioaccumulation

Drug interactions with VKAs were listed based on the drug interaction thesaurus of the French Agence Nationale de Sécurité du Médicament [26]. Pharmacokinetic and drug-drug interaction (DDI) studies involving DOAs were obtained from the literature (see Appendix). Four databases were used to identify the status 
Table 2. Targeted therapy and antithrombotic drugs prescribed

\begin{tabular}{|c|c|c|c|c|}
\hline \multirow[t]{2}{*}{ Characteristic } & \multicolumn{2}{|c|}{$\begin{array}{l}\text { Total } \\
\text { population }\end{array}$} & \multicolumn{2}{|c|}{$\begin{array}{l}\text { VKA } \\
\text { population }\end{array}$} \\
\hline & $\mathrm{n}$ & $\%$ & $\mathrm{n}$ & $\%$ \\
\hline \multicolumn{5}{|l|}{ Targeted therapy } \\
\hline Bosentan & 218 & 59.6 & 150 & 62.8 \\
\hline Ambrisentan & 61 & 16.6 & 39 & 16.3 \\
\hline Sildenafil & 180 & 49.2 & 122 & 51.0 \\
\hline Tadalafil & 90 & 24.6 & 49 & 20.5 \\
\hline Intravenous epoprostenol & 39 & 10.7 & 33 & 13.8 \\
\hline Inhaled iloprost & 10 & 2.7 & 7 & 2.9 \\
\hline Subcutaneous treprostinil & 11 & 3.0 & 5 & 2.1 \\
\hline \multicolumn{5}{|l|}{ Antithrombotic drugs } \\
\hline VKA & 239 & 65.3 & 239 & 100 \\
\hline $\mathrm{DOA}$ & 8 & 2.2 & - & - \\
\hline Antiplatelet & 90 & 24.6 & 32 & 13.4 \\
\hline VKA indication ${ }^{a}$ & - & - & 212 & 88.7 \\
\hline $\mathrm{PH}$ & - & - & 118 & 55.6 \\
\hline Venous $^{\mathrm{b}}$ & - & - & 64 & 30.2 \\
\hline Arterial $^{c}$ & - & - & 30 & 14.2 \\
\hline \multicolumn{5}{|l|}{ INR in therapeutic window $2-3$} \\
\hline$\left(\right.$ in those with VKA) ${ }^{\mathrm{d}}$ & - & - & 68 & 30.6 \\
\hline
\end{tabular}

a The indication of VKA was unknown for the remaining 27 patients. ${ }^{b}$ VKA indicated for VTE secondary prevention. ${ }^{c}$ VKA indicated for arterial indication such as AF. ${ }^{\mathrm{d}}$ INR at the time of inclusion.

(substrate, inhibitor and/or inducer) of each molecule involved in DOA transport (Pgp) or hepatic metabolism (CYP3A4), namely SuperCYP [27], Drug Bank [28], Gene Cards [29], and the summary of product characteristics. Drug inhibitor and inducer effect on Pgp and CYP3A4 were then merged into a common database. Strong inhibitors and inducers of Pgp and CYP3A4 were obtained from FDA databases [30].

Patients were then classified as having moderate or severe renal impairment if creatinine clearance was $<50 \mathrm{ml} / \mathrm{min}$ (Cockcroft and Gault formula). Liver insufficiency was defined by the serum level of alanine and/or aspartate aminotransferase $>3$ times the upper limit of normal, and/or cholestasis ( $\gamma$-glutamyl transferase and/or alkaline phosphatase $>2$ times the upper limit of normal).

Weight was recorded in order to individualize patients with low body weight, defined as $<60 \mathrm{~kg}$ [18].

\section{Statistical Analysis}

Data were analyzed using the $\mathrm{R}$ software (R Foundation for Statistical Computing, Vienna, Austria) [31]. The prevalence of potential Pgp- or CYP3A4-mediated DDIs was determined by the number of patients in the cohort for whom one or more potential Pgp- or CYP3A4-mediated DDIs were detected by matching the patients' medication database and the drug interaction database (Pgp or CYP). Percentage and median (range) were used to describe categorical and continuous variables, respectively.

\section{Results}

\section{Patient Population}

The characteristics of the study population are described in table 1 . Of the 366 patients included in the analysis, $58.5 \%$ were women, with a median age of 68 years. Most of the patients were prevalent cases (median time since first right heart catheterization: 2.4 years). One hundred and five patients $(28.7 \%)$ had a low body weight. Most of the patients belonged to WHO group I (59.6\%), followed by CTEPH (17.2\%) and PH due to lung disease (14.2\%). Chronic respiratory diseases and cardiac diseases were the most frequent comorbidities $(42 \%)$. Very few patients (1.6\%) had a history of liver disease.

\section{Treatments}

The patients were receiving a mean of $8.6( \pm 3.3)$ oral or parenteral different drugs per day at the time of evaluation (table 2). PAH-specific drugs included endothelin receptor antagonists in $76.2 \%$, phosphodiesterase-5 inhibitors in $73.8 \%$, and prostacyclin analogues in $16.4 \%$ of patients. Bosentan and sildenafil were the two most prescribed molecules. A similar proportion of patients were receiving single versus dual combination therapy for $\mathrm{PH}$ (44.5\%); bosentan-sildenafil (26\%) and bosentan-tadalafil (14\%) were the two most frequent combinations used; $11 \%$ were receiving a triple combination therapy. The ten most frequently prescribed molecules (furosemide, spironolactone, paracetamol, pantoprazole, potassium, esomeprazole, atorvastatin, levothyroxine, tramadol, allopurinol), with their known interactions, and the number of patients involved are presented in figure 1.

VKAs were prescribed in 239 patients (65.3\%), for a validated indication in 94 . Baseline characteristics of the VKA subgroup were similar to those of the whole study group (table 1), except for a higher frequency of venous or arterial comorbidities or CTEPH representing the indication for VKAs. Nearly all group IV patients (59/63) and group II patients (5/6) were anticoagulated with VKAs, versus $58.0,55.8$, and $76.2 \%$ of patients in groups I, III, and V, respectively. At the time of inclusion, the INR was in the therapeutic range (2-3) in $30.6 \%$ of patients receiving VKAs (information was missing in 17). Among patients receiving VKAs, $82.8 \%$ (198/239) had potential drug-VKA interactions according to the ANSM drug interaction thesaurus; in $62.8 \%$ of them (150/238), the potential interaction involved one of the PAH-targeted therapies, which was bosentan in all cases. No dif- 
Fig. 1. Most frequently prescribed drugs in patients with $\mathrm{PH}$ (supportive care or treatment of comorbidities), and their pharmacokinetic characteristics involved in DOA interactions. Ind = Inducer; Inh = inhibitor; Subst $=$ substrate.
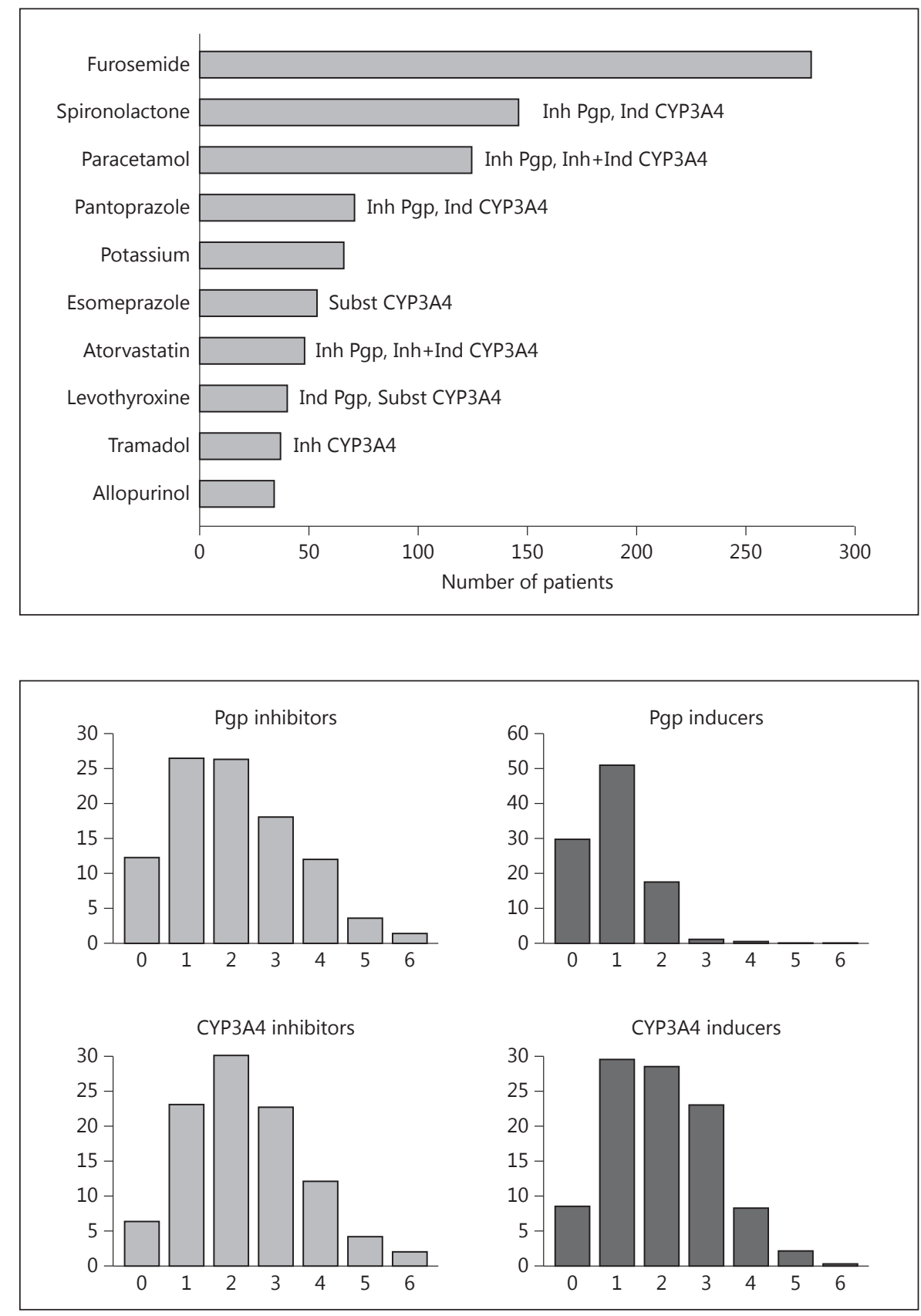

Fig. 2. Number of inhibit
prescribed per patient.

ference was observed between PH groups, comorbidity groups, or indication for VKAs. In addition, $24.6 \%$ $(90 / 366)$ of patients were treated with at least one antiplatelet agent, and 32 of them also received a VKA. DOAs were taken by only 8 patients (2.2\%): 6 patients were receiving dabigatran and 2 rivaroxaban.

Regarding DOA DDIs, $97.4 \%$ of patients received at least one inhibitor and $92.8 \%$ one inducer of drug metabolism (Pgp or CYP3A4) - bosentan in 59.6\%; 47.2\%
Table 3. Association of anticoagulants with one or more strong inhibitors or inducers

\begin{tabular}{llllll}
\hline Target & \multicolumn{2}{l}{$\begin{array}{l}\text { Number of strong } \\
\text { inhibitors }\end{array}$} & & \multicolumn{2}{l}{$\begin{array}{l}\text { Number of strong } \\
\text { inducers }\end{array}$} \\
\cline { 2 - 3 } \cline { 5 - 6 } & 1 & 2 & & 1 \\
\hline Pgp & $23(9.6 \%)$ & $4(1.7 \%)$ & & $4(1.7 \%)$ & $2(0.8 \%)$ \\
CYP3A4 & $2(0.8 \%)$ & 0 & & $151(63.2 \%)$ & $4(1.7 \%)$ \\
\hline
\end{tabular}


Table 4. Risk factors for DOA bioaccumulation

\begin{tabular}{|c|c|c|c|c|c|c|c|}
\hline & $\begin{array}{l}\text { Renal } \\
\text { failure }\end{array}$ & $\begin{array}{l}\text { Low body } \\
\text { weight }\end{array}$ & $\begin{array}{l}\text { Strong Pgp and } \\
\text { CYP3A4 inhibitor }\end{array}$ & $\begin{array}{l}1 \text { factor, } \\
\text { at least }\end{array}$ & $\begin{array}{l}\text { Patients with } \\
1 \text { factor }\end{array}$ & $\begin{array}{l}\text { Patients with } \\
2 \text { factors }\end{array}$ & $\begin{array}{l}\text { Patients with } \\
3 \text { factors }\end{array}$ \\
\hline All patients $(n=366)$ & $91(27.4)$ & $105(28.7)$ & $40(10.9)$ & $231(63.1)$ & $182(49.7)$ & $44(12)$ & $5(1.4)$ \\
\hline $\begin{array}{l}\text { Patients anticoagulated with VKAs for } \\
\text { a validated indication }(\mathrm{n}=94)\end{array}$ & $43(45.7)$ & $21(22.3)$ & $10(10.6)$ & $54(57.4)$ & $35(37.2)$ & $18(19.1)$ & $1(1.1)$ \\
\hline
\end{tabular}

Data are presented as number (\%).

received five or more inhibitors and $26.7 \%$ five or more inducers. As shown in figure $2,87.7 \%$ of patients received at least one Pgp inhibitor, $93.7 \%$ received at least one CYP3A4 inhibitor, $70.2 \%$ of patients received at least one Pgp inducer, and $91.5 \%$ received at least one CYP3A4 inducer.

Among the 239 patients receiving VKAs, 168 (70.3\%) were receiving a strong inhibitor or inducer of Pgp or CYP3A4 (table 3), and the INR was in the therapeutic window in only one third. Bosentan received by $62.8 \%$ of anticoagulated patients was the only PAH-targeted therapy with a strong CYP3A4-inducing activity; 168 $(70.3 \%)$ of the anticoagulated patients were receiving sildenafil or tadalafil, both weak inhibitors of CYP3A4. No significant differences were found in potential drug interactions between the five different $\mathrm{PH}$ groups, or according to presence of comorbidities or indication for VKA use.

\section{Risk of DOA Bioaccumulation}

The proportions of patients with at least one risk factor for DOA bioaccumulation are presented in table 4. Overall, at least one major risk factor for DOA bioaccumulation was found in 231 (63.1\%) of the whole study population, in $163(68.2 \%)$ of the anticoagulated patients, and in $54(57.4 \%)$ of the patients anticoagulated for a validated indication.

Renal failure and low body weight were the most frequent bioaccumulation risk factors in the whole population (27 and $29 \%$, respectively) as in the anticoagulated patients (31.5 and 29.7\%, respectively). Twenty-nine patients (12\%) receiving anticoagulation were also prescribed at least one strong Pgp and CYP3A4 inhibitor.

When focusing on the 94 patients anticoagulated for a validated indication, renal failure was found in 43 patients $(45.7 \%)$ and a low body weight in 21 patients (22.3\%). At least one major risk factor for DOA bioaccumulation was noted in 54 patients $(57.4 \%)$.

\section{Discussion}

This is the first cross-sectional study evaluating the risk of DOA bioaccumulation in a large cohort of unselected patients receiving PAH therapy, with a special focus on DDIs.

Among the 366 patients treated for $\mathrm{PH}$ in three distinct tertiary-care centers, 247 were receiving an anticoagulant (VKA, $\mathrm{n}=239$; DOA, $\mathrm{n}=8$ ), which was prescribed for AF or VTE in less than half of them. In patients receiving a VKA for a validated indication, replacing the VKA with a DOA would require a $50 \%$ reduction dosage in more than 1 in 2 cases, in line with the results of HOKUSAI or ENGAGE.

We decided to include PAH patients, but also other groups of $\mathrm{PH}$, because of the changing phenotype of patients seen in PAH tertiary centers. Despite the absence of a validated indication, some non-PAH patients in our cohort received an off-label PAH-targeted therapy. This trend has also been found in other cohort studies, like the ASPIRE registry [23] or others [32-34]. However, it is now clearly stated in the 2015 ESC/ERS guidelines [7] that PAH treatment is not recommended in patients with $\mathrm{PH}$ from another group than 1, and now 4 for riociguat.

Similar to the recent ASPIRE registry [23], the patients included in this study were older and had more comorbidities than in previous series [35]. Age and comorbidities can modify the risk/benefit ratio of anticoagulant therapy, and must be integrated in the discussion of anticoagulant prescription. For example, older age is associated with a higher incidence of AF and VTE, more frequent indication of anticoagulant therapy, and an increased risk of anticoagulant-induced major bleeding [36-38]. In addition, some comorbidities - like COPD [39] - may be associated with more frequent indications of anticoagulation, while others, like renal or liver dysfunction, may increase the risk of bleeding under anticoagulant therapy [36-38]. 
About $65 \%$ of the patients in this series were receiving anticoagulants, with a large variation according to the $\mathrm{PH}$ group. In patients with $\mathrm{PAH}, \mathrm{VKAs}$ were taken by $71 \%$ of those with idiopathic PAH and $46 \%$ of those with associated $\mathrm{PAH}$, similar to the recent COMPERA registry [6] (66 and 43\% of patients, respectively). Existence of a validated indication of anticoagulant therapy was unknown in the COMPERA study, and it may have influenced the results [40]. Despite the absence of validated indication, non-PAH patients frequently received an offlabel PAH-targeted therapy, and/or an anticoagulation therapy. $\mathrm{PH}$ was the only indication for anticoagulation therapy in more than half of the patients, while others were treated for AF or VTE in the setting of frequent comorbidities.

At the time of inclusion, DOAs were at the very beginning of their availability in France. It may explain the very low number of patients included and receiving DOAs. The use of DOAs is now progressively increasing, raising concerns about potential adverse events. The European Society of Cardiology recommends that DOAs 'should be considered rather than adjusted-dose VKAs (INR 2-3) for most patients with nonvalvular AF, based on their net clinical benefit' [41]. Importantly, the net clinical benefit is mainly driven by a reduction in the risk of major bleeding (including intracranial bleeding), whereas dabigatran and rivaroxaban are associated with an increased risk of gastro-intestinal bleeding when compared to VKAs. The external validity of such benefit is uncertain in the setting of $\mathrm{PH}$, as gastrointestinal bleeding was the most frequent bleeding in the single study evaluating the safety of VKAs in $\mathrm{PH}$ patients [24].

Although drug interactions with VKAs are generally corrected for by measurement of the INR and dose adaptation, the net clinical benefit of DOAs may vary largely in the event of altered DOA pharmacokinetics [22]. Similar to a previous study on AF [42], we found that $\mathrm{PH}$ patients frequently received Pgp and CYP-modulator drugs. A lower DOA concentration may be anticipated in patients receiving bosentan $(60 \%$ of the cohort). Major bleeding secondary to bioaccumulation is one of the most feared complications. This is particularly true in the setting of $\mathrm{PH}$, where the real place of anticoagulation is still under debate. Therefore, the most recent trials evaluating DOA have integrated a 50\% dose reduction in patients at risk of bioaccumulation. This strategy was prospectively validated in trials including about 30,000 patients with VTE or AF, where dose reduction preserved the safety advantage without losing efficacy [22]. Our data suggest that significant bioaccu-

Anticoagulant Therapy and Pulmonary Hypertension mulation of DOA may occur in more than 1 in 2 patients with $\mathrm{PH}$, including those anticoagulated for a validated indication. Unfortunately, $\mathrm{PH}$ patients at risk of DOA bioaccumulation could not be easily identified by their comorbidities or the indication of anticoagulation therapy.

It is unclear whether the association of several nonstrong inhibitors may have additive effects, as for digoxin [43]; however, in theory it may dramatically increase the risk of DOA bioaccumulation, as half of our patients received at least five inhibitors. It is also unclear whether enzyme or transporter induction could compensate for their inhibition by another drug, e.g. whether the effect of CYP inducers could offset the effect of Pgp inhibitors. Of note, a pharmacodynamics interaction was also found in $13 \%$ of patients taking VKAs who also received antiplatelet agents; in the setting of $\mathrm{AF}$, this association has been shown to increase the risk of fatal bleeding and gastrointestinal bleeding [44] and should be avoided, except in highly specialized centers in patients with recent acute coronary syndrome and stent insertion, as recently stated in European recommendations [45].

There were several limitations to this study, including its cross-sectional design with no long-term follow-up. However, the study population included a large sample of patients from three different centers, all involved in a national ongoing registry [4], and was very similar to that included in recent $\mathrm{PH}$ registries such as ASPIRE [23]. Only adult patients were included, limiting heterogeneity. Drugs were evaluated only at the time of the evaluation, and potential drug interactions due to short course treatments were not evaluated (e.g. antibiotics). The list of strong modulators was that provided by the FDA [30], and we cannot exclude that some potential interactions may not be listed as yet. Finally, we included only body weight as a risk factor and not body mass index or body surface area, but it was in order to follow the recommendation of health authorities like EMA regarding the design of DOA trials.

In conclusion, we found that a bioaccumulation of DOAs may occur in a majority of patients treated for $\mathrm{PH}$. Their use in patients with $\mathrm{PAH}$ or other forms of $\mathrm{PH}$, and without another indication for anticoagulation, is currently not supported. The risk of bioaccumulation seems to decrease in patients anticoagulated for a validated indication. Management of AF or VTE and choice of therapy should integrate the potential risk of interaction, bioaccumulation, and potentially bleeding, and should be discussed on an individual basis. 


\section{Acknowledgment}

The authors thank the physicians who participated in the care of the patients: Drs L. Bisch, I. Court-Fortune, E. Frappé, J.B. Gaultier, N. Glas (all in Centre Hospitalier Universitaire de St-
Etienne); Drs F. Piegay, J. Traclet, and Ms S. Zeghmar who contributed data to the registry (all in Hospices Civils de Lyon); Ms L. Dubouloz, Ms M. Jondot (all in Centre Hospitalier Universitaire de Grenoble). The authors also thank LANIEL Traduction (St-Etienne, France), for correcting the English language.

\section{Appendix}

\begin{tabular}{|c|c|c|c|c|}
\hline & Dabigatran etexilate & Rivaroxaban & Apixaban & Edoxaban \\
\hline $\begin{array}{l}\text { Pharmacologic } \\
\text { target }\end{array}$ & Factor IIa & Factor Xa & Factor Xa & Factor Xa \\
\hline Bioavailability & $3-7 \%$ & $66 \%$ & $50 \%$ & $60 \%$ \\
\hline $\begin{array}{l}\text { Plasma protein } \\
\text { binding }\end{array}$ & $35 \%$ & $95 \%$ & $87 \%$ & $>97 \%$ \\
\hline Half-life & $12-17 \mathrm{~h}$ & $5-9 h$ & $8-15 \mathrm{~h}$ & $9-11 \mathrm{~h}$ \\
\hline $\begin{array}{l}\text { Transport and } \\
\text { metabolism }\end{array}$ & $\begin{array}{l}\text { CYP: no } \\
\text { Pgp: substrate }\end{array}$ & $\begin{array}{l}\text { CYP3A4: substrate } \\
\text { Pgp: substrate, weak inhibitor }\end{array}$ & $\begin{array}{l}\text { CYP3A4: substrate } \\
\text { Pgp: substrate }\end{array}$ & $\begin{array}{l}\text { CYP3A4: substrate } \\
\text { Pgp: substrate }\end{array}$ \\
\hline Elimination & $\begin{array}{l}80 \% \text { unchanged drug } \\
20 \% \text { active metabolites }\end{array}$ & $\begin{array}{l}45 \% \text { unchanged drug } \\
55 \% \text { inactive metabolites }\end{array}$ & $\begin{array}{l}75 \% \text { unchanged drug } \\
25 \% \text { inactive metabolites }\end{array}$ & $\begin{array}{l}75 \% \text { unchanged drug } \\
25 \% \text { inactive metabolites }\end{array}$ \\
\hline Route of elimination & $\begin{array}{l}\text { Kidney } \approx 80 \% \\
\text { Biliary } \approx 20 \%\end{array}$ & $\begin{array}{l}\text { Kidney } \approx 70 \% \\
\text { Biliary } \approx 30 \%\end{array}$ & $\begin{array}{l}\text { Kidney } \approx 25 \% \\
\text { Biliary } \approx 75 \%\end{array}$ & $\begin{array}{l}\text { Kidney } \approx 35 \% \\
\text { Biliary } \approx 65 \%\end{array}$ \\
\hline $\begin{array}{l}\text { Special } \\
\text { population of } \\
\text { accumulation }\end{array}$ & $\begin{array}{l}\text { Elderly people } \\
\text { Liver disease } \\
\text { Renal impairment }\end{array}$ & $\begin{array}{l}\text { Elderly people } \\
\text { Liver disease } \\
\text { Renal impairment }\end{array}$ & Not reported & Not reported \\
\hline $\begin{array}{l}\text { Drug } \\
\text { interactions }\end{array}$ & $\begin{array}{l}\text { Pgp inhibitors: amiodarone, } \\
\text { dronedarone, clarithromycin, } \\
\text { ketoconazole, verapamil, quinidine, } \\
\text { phenothiazine, carboxylic acid, } \\
\text { cyclosporine, thioxanthenes } \\
\text { Pgp inducers: rifampicin, Saint } \\
\text { John's Wort, carbamazepine, } \\
\text { phenytoin, dexamethasone } \\
\text { PD: antiplatelet agents (clopidogrel), } \\
\text { NSAIDs (aspirin, naproxen, } \\
\text { diclofenac), pantoprazole }\end{array}$ & $\begin{array}{l}\text { CYP3A4 and Pgp inhibitors: } \\
\text { ketoconazole, itraconazole, } \\
\text { voriconazole, posaconazole, } \\
\text { ritonavir, clarithromycin, } \\
\text { erythromycin, diltiazem, } \\
\text { amiodarone, verapamil, quinidine, } \\
\text { naproxen } \\
\text { CYP3A4 and Pgp inducers: } \\
\text { rifampicin, St. John's Wort, } \\
\text { phenytoin, carbamazepine, } \\
\text { phenobarbital } \\
\text { PD: antiplatelet agents (clopidogrel), } \\
\text { NSAIDs (aspirin, naproxen, } \\
\text { diclofenac) }\end{array}$ & $\begin{array}{l}\text { CYP3A4 and Pgp inhibitors: azole } \\
\text { antifungals, protease inhibitors, } \\
\text { diltiazem, naproxen, amiodarone, } \\
\text { verapamil, quinidine } \\
\text { CYP3A4 and Pgp inducers: } \\
\text { phenytoin, carbamazepine, } \\
\text { phenobarbital, St. John's Wort } \\
\text { PD: anticoagulants, antiplatelet } \\
\text { agents (clopidogrel), NSAIDs } \\
\text { (aspirin, naproxen, diclofenac) }\end{array}$ & $\begin{array}{l}\text { Pgp inhibitors: verapamil, quinidine, } \\
\text { dronedarone } \\
\text { PD: anticoagulants, antiplatelet } \\
\text { agents (clopidogrel), NSAIDs } \\
\text { (aspirin, naproxen, diclofenac) }\end{array}$ \\
\hline
\end{tabular}

$\mathrm{PD}=$ Pharmacodynamic

\section{References}

1 Simonneau G, Gatzoulis M, Adatia I, et al: Updated clinical classification of pulmonary hypertension. J Am Coll Cardiol 2013;62(25 suppl):D34-D41.

- 2 Tuder RM, Archer SL, Dorfmüller P, et al: Relevant issues in the pathology and pathobiology of pulmonary hypertension. J Am Coll Cardiol 2013;62(25 suppl):D4-D12.

-3 Herve P, Humbert M, Sitbon O, et al: Pathobiology of pulmonary hypertension. The role of platelets and thrombosis. Clin Chest Med 2001;22:451-458.

4 Humbert M, Sitbon O, Chaouat A, et al: Survival in patients with idiopathic, familial, and anorexigen-associated pulmonary arterial hypertension in the modern management era. Circulation 2010;122:156-163. $\checkmark 5$ Caldeira D, Loureiro MJ, Costa J, Pinto FJ, Ferreira JJ: Oral anticoagulation for pulmonary arterial hypertension: systematic review and meta-analysis. Can J Cardiol 2014;30: 879-887.

6 Olsson KM, Delcroix M, Ghofrani HA, et al: Anticoagulation and survival in pulmonary arterial hypertension: results from the Comparative, Prospective Registry of Newly Initiated Therapies for Pulmonary Hypertension (COMPERA). Circulation 2014;129:57-65.

7 Galiè N, Humbert M, Vachiery J-L, et al: 2015 ESC/ERS Guidelines for the diagnosis and treatment of pulmonary hypertension. Eur Heart J 2015;46:ehv317.
8 Bertoletti L, Delavenne X, Montani D: Antithrombotics in pulmonary hypertension: more work needed before we turn to newer agents! Eur Respir J 2013;41:775-777.

9 BAATAF Investigators: The effect of lowdose warfarin on the risk of stroke in patients with nonrheumatic atrial fibrillation. The Boston Area Anticoagulation Trial for Atrial Fibrillation Investigators. N Engl J Med 1990; 323:1505-1511.

10 Verstuyft C, Delavenne X, Rousseau A, et al: A pharmacokinetic-pharmacodynamic model for predicting the impact of CYP2C9 and VKORC1 polymorphisms on fluindione and acenocoumarol during induction therapy. Clin Pharmacokinet 2012;51:41-53. 
11 Schulman S, Kearon C, Kakkar AK, et al: Dabigatran versus warfarin in the treatment of acute venous thromboembolism. N Engl J Med 2009;361:2342-2352.

12 Connolly SJ, Ezekowitz MD, Yusuf S, et al: Dabigatran versus warfarin in patients with atrial fibrillation. N Engl J Med 2009;361: 1139-1151.

13 Patel MR, Mahaffey KW, Garg J, et al: Rivaroxaban versus warfarin in nonvalvular atrial fibrillation. N Engl J Med 2011;365:883-891.

-14 Büller HR, Prins MH, Lensin AWA, et al: Oral rivaroxaban for the treatment of symptomatic pulmonary embolism. N Engl J Med 2012; 366:1287-1297.

$\checkmark 15$ Connolly SJ, Eikelboom J, Joyner C, et al: Apixaban in patients with atrial fibrillation. $\mathrm{N}$ Engl J Med 2011;364:806-817.

16 Agnelli G, Büller HR, Cohen A, et al: Oral apixaban for the treatment of acute venous thromboembolism. N Engl J Med 2013;369: 799-808.

-17 Giugliano RP, Ruff CT, Braunwald E, et al: Edoxaban versus warfarin in patients with atrial fibrillation. N Engl J Med 2013;369: 2093-2104.

18 Büller HR, Décousus H, Grosso MA, et al: Edoxaban versus warfarin for the treatment of symptomatic venous thromboembolism. N Engl J Med 2013;369:1406-1415.

$\checkmark 19$ Castellucci LA, Cameron C, Le Gal G, et al: Clinical and safety outcomes associated with treatment of acute venous thromboembolism: a systematic review and meta-analysis. JAMA 2014;312:1122-1135.

20 Delavenne X, Ollier E, Basset T, et al: A semimechanistic absorption model to evaluate drug-drug interaction with dabigatran: application with clarithromycin. Br J Clin Pharmacol 2013;76:107-113.

-21 Lega J-C, Bertoletti L, Gremillet C, Boissier C, Mismetti P, Laporte S: Consistency of safety profile of new oral anticoagulants in patients with renal failure. J Thromb Haemost 2014; 12:337-343.

22 Ruff CT, Giugliano RP, Braunwald E, et al: Association between edoxaban dose, concentration, anti-Factor Xa activity, and outcomes: an analysis of data from the randomised, double-blind ENGAGE AF-TIMI 48 trial. Lancet 2015;6736:1-8.

23 Hurdman J, Condliffe R, Elliot CA, et al: ASPIRE registry: assessing the Spectrum of Pulmonary hypertension Identified at a REferral centre. Eur Respir J 2012;39:945-955.
24 Henkens IR, Hazenoot T, Boonstra A, Huisman MV, Vonk-Noordegraaf A: Major bleeding with vitamin $\mathrm{K}$ antagonist anticoagulants in pulmonary hypertension. Eur Respir J DOI: $10.1183 / 09031936.00039212$.

25 van Giersbergen PLM, Halabi A, Dingemanse J: Single- and multiple-dose pharmacokinetics of bosentan and its interaction with ketoconazole. Br J Clin Pharmacol 2002;53:589595.

26 ANSM: Thesaurus des interactions médicamenteuses. Saint Denis, ANSM, 2013.

27 Preissner S, Kroll K, Dunkel M, et al: SuperCYP: a comprehensive database on Cytochrome P450 enzymes including a tool for analysis of CYP-drug interactions. Nucleic Acids Res 2010;38(database issue):D237D243.

28 Drug Bank: Open Data Drug and Drug Target Database. www.drugbank.ca.

29 Weizmann Institute of Science: Gene Cards ${ }^{\circledR}$, The Human Gene Database. Rehovot, Weizmann Institute of Science.

30 US Food and Drug Administration: Drug Development and Drug Interactions: Table of Substrates, Inhibitors and Inducers. Silver Spring, US Food and Drug Administration, 2011.

31 R: The R Project for Statistical Computing. Vienna, R Foundation for Statistical Computing.

32 Calcaianu G, Canuet M, Schuller A, Enache I, Chaouat A, Kessler R: Pulmonary arterial hypertension-specific drug therapy in COPD patients with severe pulmonary hypertension and mild-to-moderate airflow limitation. Respiration DOI: 10.1159/000441304.

-33 Adir Y, Humbert M, Sitbon O, et al: Outof-proportion pulmonary hypertension and heart failure with preserved ejection fraction. Respiration 2013;85:471-477.

34 Girard A, Jouneau S, Chabanne C, et al: Severe pulmonary hypertension associated with COPD: hemodynamic improvement with specific therapy. Respiration 2015;90:220228.

35 Rich S, Kaufmann E, Levy PS: The effect of high doses of calcium-channel blockers on survival in primary pulmonary hypertension. N Engl J Med 1992;327:76-81.

-36 Decousus H, Tapson VF, Bergmann J-F, et al: Factors at admission associated with bleeding risk in medical patients: findings from the IMPROVE investigators. Chest 2011;139:6979.
37 Ruíz-Giménez N, Suárez C, González R, et al: Predictive variables for major bleeding events in patients presenting with documented acute venous thromboembolism. Findings from the RIETE Registry. Thromb Haemost 2008; 100: 26-31.

38 Apostolakis S, Lane DA, Guo Y, Büller H, Lip GYH: Performance of the HEMORR2HAGES, ATRIA, and HAS-BLED bleeding riskprediction scores in patients with atrial fibrillation undergoing anticoagulation. J Am Coll Cardiol 2012;60:861-867.

39 Bertoletti L, Quenet S, Mismetti P, et al: Clinical presentation and outcome of venous thromboembolism in COPD. Eur Respir J 2012;39:862-868.

40 Bertoletti L, Mismetti P, Decousus H: Letter by Bertoletti et al. regarding article, 'Anticoagulation and survival in pulmonary arterial hypertension: results from the Comparative, Prospective Registry of Newly Initiated Therapies for Pulmonary Hypertension (COMPERA)'. Circulation 2014;130:e108.

41 Camm AJ, Lip GYH, De Caterina R, et al: 2012 focused update of the ESC Guidelines for the management of atrial fibrillation: an update of the 2010 ESC Guidelines for the management of atrial fibrillation. Developed with the special contribution of the European Heart Rhythm Association. Eur Heart J 2012;33: 2719-2747.

42 Jungbauer L, Dobias C, Stöllberger C, Weidinger $\mathrm{F}$ : The frequency of prescription of $\mathrm{P}$ glycoprotein-affecting drugs in atrial fibrillation. J Thromb Haemost 2010;8:2069-2070.

-43 Englund G, Hallberg P, Artursson P, Michaëlsson K, Melhus H: Association between the number of coadministered P-glycoprotein inhibitors and serum digoxin levels in patients on therapeutic drug monitoring. BMC Med 2004;2:8.

44 Hansen ML, Sørensen R, Clausen MT, et al: Risk of bleeding with single, dual, or triple therapy with warfarin, aspirin, and clopidogrel in patients with atrial fibrillation. Arch Intern Med 2010;170:1433-1441.

45 Heidbuchel H, Verhamme P, Alings M, et al: Updated European Heart Rhythm Association Practical Guide on the use of non-Vitamin $\mathrm{K}$ antagonist anticoagulants in patients with non-valvular atrial fibrillation. Europace 2015;17:1467-1507. 